\title{
Total quality management tools and techniques for improving service quality and client satisfaction in the healthcare environment: A qualitative systematic review
}

\author{
Dana Grossu-Leibovica ${ }^{1}$ and Henrijs Kalkis ${ }^{2}$ \\ ${ }^{1}$ Riga Stradins University, Faculty of Business, Management and Economics, Department of manage- \\ ment, Riga, Latvija \\ ${ }^{2}$ University of Latvia, Faculty of Business, Management and Economics, Department of management, \\ Riga, Latvia
}

\begin{abstract}
The aim of the given research is to analyse total quality management tools for improving service quality and client satisfaction in healthcare settings through a systematic qualitative review. Data was collected through the web of sciences (WOS), Scopus, EBSCO, PubMed, and Medline. Initially, we found 573 articles from all the sources, but after eliminating the non-relevant articles, only 24 usable articles were finalized. Furthermore, 12 articles were purely related to TQM, service quality, and client satisfaction. This study concludes that TQM practices and tools improve service quality and client satisfaction in healthcare organizations. This study provides excellent managerial and practical insights. Managers should implement the TQM tools to improve service quality and client satisfaction. This way, customer satisfaction is enhanced, and patient satisfaction is improved, leading to high operational and overall performance. This study also reveals a need for further studies to clarify the role of TQM tools on service quality and patient satisfaction.
\end{abstract}

\section{Introduction}

Through globalization, all business processes, environmental factors, external pressures, and development teams focus on implementing a comprehensive system for quality management (TQM) [1]. The implementation of these methods provides the company with competitive opportunities and is also seen as a source of service improvement and client satisfaction [2]. In recent years, the concept of quality has become one of the main objectives of customer satisfaction, which can be achieved by responding to customer needs quickly [3]. Quality is divided into good and objective. So far, it is associated with well-being and the hallmarks of solidarity and efficiency in the production and delivery of products and services [4,5]. Quality is a significant concern for the healthcare industry, where there are many issues related to the existence of an organization. For example, health care providers must use professional standards and avoid legal and ethical problems to survive economically and socially [6,7]. The health industry has been treating these problems for more than a decade [8]. Healthcare groups are exposed to a wide range of risks related to customer satisfaction and health care 
services [9]. Looking back, compared to the current state of the hospital, one can see that this area is growing through design, coordination, procedures, procedures, and diagnostic procedures [10].

Changing circumstances and tough competition lead health teams to pay more attention to the efficiency and effectiveness of their practice and this organization as a whole. $\mathrm{Nu}-$ merous researchers have addressed this problem but focus more on nursing work [11-14]. This concern is that nurses represent several health care providers and can play an essential role in the implementation of clinical plans and practices [15]. So far, many researchers have focused on new aspects of hospital management, such as rising drug costs, rapid technology changes, patient satisfaction, and industry pressures-social and economic development. Researchers have found that the increasing demand for better care and higher drug and health care costs affect people with multiple illnesses [16]. Many researchers focus on quality management in the healthcare industry, considering the general principles of quality management as an effective method of quality management in the healthcare industry [17]. By applying comprehensive management principles, companies can achieve service quality, and customer satisfaction [18]. Within the globalization period, the adoption and application of TQM standards create complexity and competition to prevent the healthcare industry from falling behind [19]. The analysts said that this was achieved by applying TQM standards and increasing processing performance, which would improve the company's performance. TQM works with continuous improvement work, innovation and change management systems, and integrating and delivering global business processes [20,21].

TQM implementation is easy to use and straightforward, so you need to consider the key to success. If TQM standards are distorted or not used, not all benefits are guaranteed, and performance will not be achieved. In other words, TQM needs to be put in place by traffic and connected services in different units. Although many studies have shown positive results using TQM in organizational efficiency and effectiveness, its results are inconclusive $[5,9,22]$. TQM has many important factors for the success of your implementation. These factors determine performance during TQM training [23]. These factors indicate the successful implementation of the overall quality control principles, and studies have shown a positive relationship between these factors and the company's financial performance [24]. The problem with TQM testing is in the healthcare industry. A few studies have focused on the health sector, and many are related to the manufacturing industry. Therefore, it is important to examine the relationship between TQM tools and techniques, service quality, and client satisfaction in healthcare settings. The present studies are not sufficient to describe the correct path and other details that will be needed in future studies [25]. The positive impact should be identified by using a healthcare industry model, the new TQM. This study conducted an extensive review of important literature, with many researchers [3,9,14,22,25]. Focusing on general TQM and some focusing on general condition [2,7,12,20,26]. I found this to be a focus. It focuses on TQM implementation. Therefore, this magazine is in the health department.

\section{Qualitative Systematic Review}

Qualitative Systematic Review (QSR) identifies and evaluates different studies using a systematic approach. QSR is used to extract well-defined information in a paper to create a survey question. Single-lens reflex cameras have been used in medicine for decades but have recently gained the attention of researchers [27]. The SLR process includes many things, including explaining test questions, defining inclusion, defining discharge, retrieving relevant documents from databases, better review of existing documents, review of results and presentation of discussions. 
Table 1. Keywords for Qualitative Systematic Review.

\begin{tabular}{|c|c|c|c|c|c|c|}
\hline $\begin{array}{c}\text { Sr } \\
\text { No. }\end{array}$ & Keyword & WOS & Scopus & EBSCO & Medline & WebMD \\
\hline 1 & Total Quality Management & $\nabla$ & 西 & $\nabla$ & 目 & 口 \\
\hline 2 & $\begin{array}{l}\text { Total Quality Management } \\
\text { AND Customer Satisfaction }\end{array}$ & $\bar{\nabla}$ & $\bar{\nabla}$ & $\bar{\nabla}$ & $\bar{\nabla}$ & $\bar{\nabla}$ \\
\hline 3 & $\begin{array}{l}\text { Total Quality Management } \\
\text { AND Customer Experience }\end{array}$ & $\nabla$ & $\nabla$ & $\nabla$ & $\nabla$ & $\nabla$ \\
\hline 4 & $\begin{array}{l}\text { Total Quality Management } \\
\text { AND Client Satisfaction }\end{array}$ & $\nabla$ & $\nabla$ & $\nabla$ & $\nabla$ & 可 \\
\hline 5 & $\begin{array}{l}\text { Total Quality Management } \\
\text { AND Service Quality }\end{array}$ & 可 & $\nabla$ & $\nabla$ & $\nabla$ & $\nabla$ \\
\hline 6 & $\begin{array}{l}\text { Total Quality Management } \\
\text { AND Service Experience }\end{array}$ & $\nabla$ & $\nabla$ & $\nabla$ & $\nabla$ & 口 \\
\hline 7 & $\begin{array}{l}\text { Total Quality Management } \\
\text { AND Patient Satisfaction }\end{array}$ & 可 & $\nabla$ & $\nabla$ & $\nabla$ & 四 \\
\hline 8 & $\begin{array}{l}\text { Total Quality Management } \\
\text { AND Healthcare Management }\end{array}$ & $\nabla$ & V & $\nabla$ & V & $\nabla$ \\
\hline 9 & $\begin{array}{l}\text { Total Quality Management } \\
\text { AND Service Quality AND } \\
\text { Customer Satisfaction AND } \\
\text { Health Sector }\end{array}$ & $\nabla$ & V & $\nabla$ & $\nabla$ & $\nabla$ \\
\hline
\end{tabular}

Figure 1 below shows the details of the report extracted from the database above. WOS 1920, Scopus 2253, Medline 4120, EBSCO 2789 and PubMed 435 articles. Initially, 11517 research papers were extracted through the keywords. After careful analysis of the names and journals of the collected articles, we obtained a total of 573 articles related to our research purpose. WOS 134, Scopus 186, Medline 11, EBSCO 225 and PubMed 17. After applying the qualitative review criteria, we obtained a total of 12. items. To conduct a comprehensive study, the methods used in this article also include identifying and evaluating TQM predictors and their impact on performance. This is done by identifying prophets or important figures from 12 articles examining TQM tools and techniques in service quality and patient satisfaction in the healthcare environment. These studies revealed that TQM tools and techniques implementation reflect the impact of service quality performance and patients' satisfaction in the healthcare sector. The development and implementation of input methods are determined by linking and integrating research, authors, research, community research, change, change criteria, and results from each selected topic. Twelve papers extracted according to all criteria of the QSR procedure were analyzed and divided into groups.

The extracted papers are gathered across different countries, but one thing that is found surprising in this review is that most of the research on TQM tools, service quality, and patients satisfaction in the healthcare sector is done mainly in middle eastern and south Asian countries, leaving the developed nations behind.

A recent study collected data from medical institutions, system management, training programs and development. Research shows that these factors positively impact the service quality and performance of an organization [28]. Similarly, another study examined a hospital in Jordan and examined the impact of TQM on performance and found that TQM was the most critical factor in all ongoing improvements [29]. Comprehensive research of hospitals in Pakistan focuses on HR TQM, TQM processing and TQM quality infrastructure. They collected data from 239 hospital staff and found that TQM was actively organizing and efficiently organizing [30]. A similar analysis was performed at the Jordanian health facility where TQM KPI was tested, and positive results [31]. 


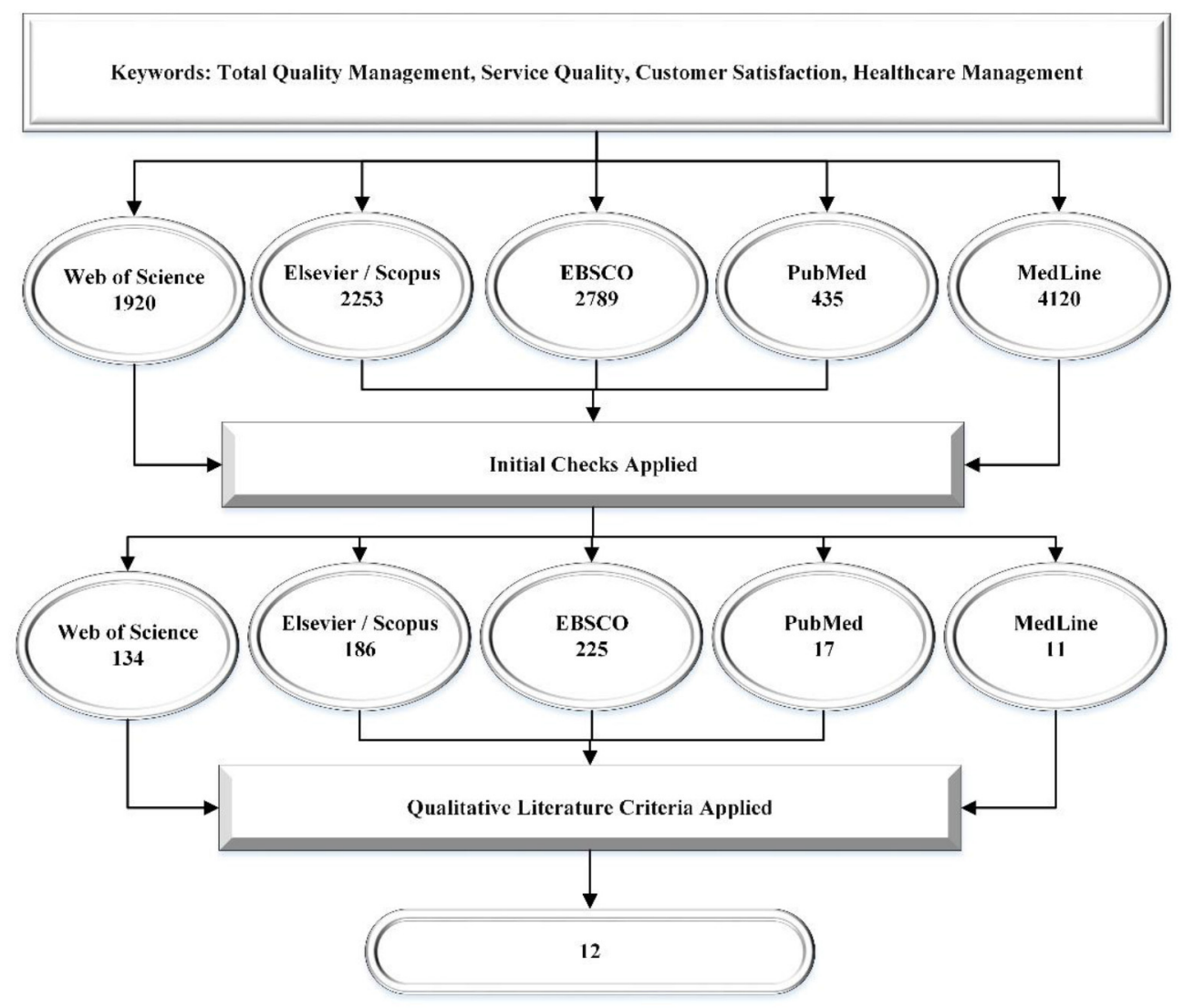

Figure 1. Qualitative Systematic Review.

Management's engagement, continual improvement, decision-making process, customer and employee training are indicators of overall quality management of Iranian healthcare companies and show precise positive results. Kumar et al. use a similar design approach for their experiments. Another study was found in the Iranian military health centre using a similar model and method. To confirm the implementation of the TQM factor with increased satisfaction in terms of efficiency and performance, continued engagement and quality service delivery. Another study used an experimental design to study the efficacy and performancerelated interventions of TQM in healthcare institutions. The results show an essential effect in increasing patient satisfaction [32]. Similarly, another research used a similar method to study Iranian hospitals that applied the principles of TQM. The results show that the application of TQM principles positively impacts compliance, efficiency, and performance [33].

Furthermore, studies like [34] suggest that these factors can positively influence employee empowerment and increase efficiency. In another study, we contacted managers and provided feedback on the following TQM estimates: Results show that these predictions positively impact performance [34]. In another survey conducted in a public hospital in Jordan. Analyse the impact on TQM predictions and performance using samples such as Leadership engagement, customer focus, employee engagement, culture, education, and quality standards were considered predictors and impacts on efficiency were identified and significantly posi- 
Table 2. Articles Included in SLR.

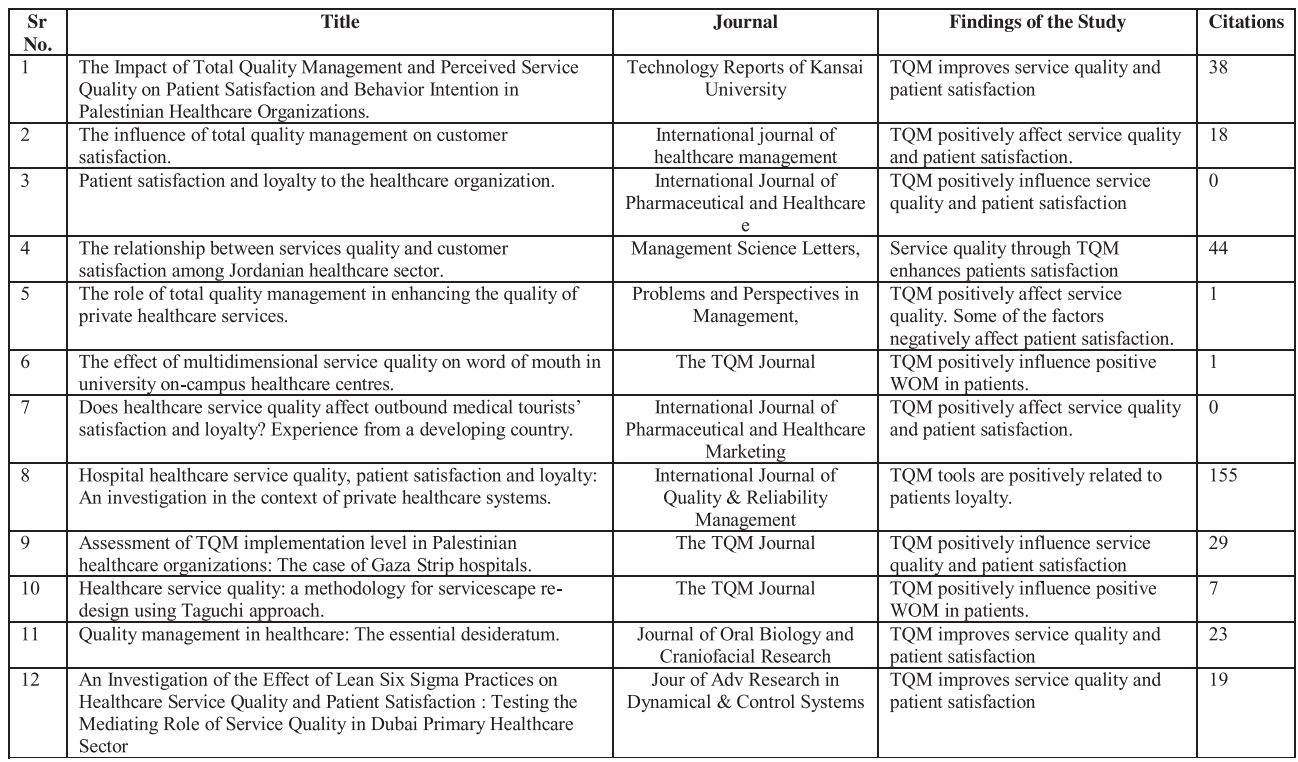

tive [35]. Study [36] discuss the literature on TQM implementation as well as its impact on processing performance. He said innovation was a factor in reducing wages in many studies.

Similarly, in another study, it was found to incorporate overall management control into the performance and performance of hospitals where an agile management system improved hospital performance. Hospitalization by reducing labour costs [37]. Study [38] shown that good quality control practices positively impact the quality of hospital care. The above discussion qualifies that TQM tools and techniques, when implemented, create a tremendous significant positive impact on service quality. It is also observed that the impact on perceived service quality and actual service quality both are found significantly positive.

Furthermore, TQM also impacts client/patients' satisfaction positively. At the same time, some studies show that service quality mediates the relationship between TQM tools and techniques implementation and client's satisfaction in healthcare settings. Table 2 explains the highly effective studies through this literature on TQM tools and techniques, services quality, and client's satisfaction in the healthcare environment.

\section{Discussions and conclusions}

This type of analysis is essential for analysts and managers, while TQM has become a critical management method to improve research productivity. TQM is in practice in almost all sectors of life, but when it comes to the healthcare sector, it has become imperative to analyse its role due to the pandemic, e.g., COVID-19. Through this research, we had an opportunity to clarify the role of TQM tools and techniques in service quality and client's satisfaction in the healthcare sector. Therefore, we have developed a framework for qualitative literature analysis. This study reviews the work on TQM in the health sector and checks for service quality improvements and patients' satisfaction by reviewing work done from 1998-2021. We have looked into different aspects and checked for the growing trends, developing programs, and integrations for TQM health assessments. It helps to check the current TQM data status, find the space in this document and identify the area for further analysis. In doing so, it contributes 
to the health sector analysis and developments in TQM. Document results show that TQM is performing health and wellness, and applying TQM to the defined KPI provides a higher level. By implementing TQM, healthcare professionals can respond more quickly, focusing on patient care and ultimately improving productivity. Results obtained after the end of this study highlight the benefits of healthcare professionals in the implementation and implementation of TQM in hospitals and clinics. It seeks to improve the work of health professionals as well as improve organizational performance.

This study is essential for the policymakers, regulators, practitioners, and managers because it has shown all the recent trends related to the TQM in the healthcare sector. We have observed the severe impact of TQM on the healthcare sector in a positive manner. Though healthcare organizations practice TQM in various aspects, it is still deficient. Hospitals and other health facility providers should follow the guidelines provided by the international organization for standardization. By following these practices, hospitals can reduce their cost by enhancing their efficiency, which increases overall performance. On the other hand, healthcare firms can also increase customer satisfaction, i.e., patients' loyalty, by enhancing service quality by implementing the TQM tools and techniques.

Future research should expand the topic of this report to clarify further research, the different research methods used, and the one and why TQM works.

\section{Limitations and future recommendations}

Although this study reviewed the literature on quality control and organizational effectiveness, there are some limitations. Initially, data availability was an issue, and for a while, only existing elements were collected. Second, some databases were selected and maintained, and links to other databases were not created for financial reasons. Third, this study, which targets only medical facilities and other institutions, has been omitted. We recommend that you follow future guidelines with these limitations in mind. First, you will need to contact several public, private, and private databases to gather more published articles. Second, the research in this study is primarily about hospital reviews, and most of the pharmaceutical companies and manufacturers, such as pharmaceutical companies to be considered in future studies, are ignored. Fourth, this study focuses on the effectiveness of the TQM organization, ignoring other viewpoints. Therefore, other aspects should be considered in future studies. Finally, this review found most articles from Iran, China, India, Pakistan and Jordan. B Few items were found for Europe and America: USA, Canada, UK, Australia, Europe. These areas should be considered when considering the implementation of TQM in healthcare.

\section{References}

[1] K.B. Ooi, B. Lin, B.I. Tan, and A.Y.L. Chong, Are TQM practices supporting customer satisfaction and service quality? Journal of Services Marketing 25(6), pp. 410-419 (2011)

[2] T.F. Alfalah, Total Quality Management Tools: Are they Necessary for Improving Service Quality and Customer Satisfaction? International Review of Management and Marketing 7(3), pp. 121-125 (2017)

[3] D. Pattanayak, M. Koilakuntla, and P. Punyatoya, Investigating the influence of TQM, service quality and market orientation on customer satisfaction and loyalty in the Indian banking sector. International Journal of Quality \& Reliability Management (2017)

[4] H. Yas, A. Jusoh, A.F. Abbas, A. Mardani, and K.M. Nor, A review and bibliometric analysis of service quality and customer satisfaction by using Scopus database, International Journal of Management (IJM) 11(8) (2020) 
[5] M. Jeong, H. Oh, Quality function deployment: An extended framework for service quality and customer satisfaction in the hospitality industry. International Journal of Hospitality Management 17(4), pp. 375-390 (1998)

[6] W.Y. Sit, K.B. Ooi, S.P. Loke, and G.T.W. Han, TQM and service quality: a survey of commercial banking industry in Malaysia. International Journal of Services, Economics and Management 3(1), pp. 78-91 (2011)

[7] U. Lenka, D. Suar, and P.K. Mohapatra, Soft and hard aspects of quality management practices influencing service quality and customer satisfaction in manufacturingoriented services, Global Business Review 11(1), pp. 79-101 (2010)

[8] E.N. Torres, Deconstructing service quality and customer satisfaction: Challenges and directions for future research. Journal of Hospitality Marketing \& Management 23(6), pp. 652-677 (2014)

[9] N.J. Slack, G. Singh, The effect of service quality on customer satisfaction and loyalty and the mediating role of customer satisfaction: Supermarkets in Fiji. The TQM Journal 32(3), pp. 543-558 (2020)

[10] P. Hernon, D.A. Nitecki, E. Altman, Service quality and customer satisfaction: An assessment and future directions, The journal of academic librarianship 25(1), pp. 9-17 (1999)

[11] T.F. Alfalah, Total Quality Management Tools: Are they Necessary for Improving Service Quality and Customer Satisfaction?, International Review of Management and Marketing 7(3), pp. 121-125 (2017)

[12] M. Aqsa, M. Risal, M. and R. Nur, Total Quality Management and Service Quality on Customer Satisfaction in Public Services, PINISI Discretion Review 4(2), pp. 359-368 (2021)

[13] A.A. Zaid, S.M. Arqawi, R.M.A. Mwais, M.J. Al Shobaki, and S.S. Abu-Naser, The Impact of Total Quality Management and Perceived Service Quality on Patient Satisfaction and Behavior Intention in Palestinian Healthcare Organizations, Technology Reports of Kansai University 62(03), pp. 221-232 (2020)

[14] A. Aburayya, M. Alshurideh, A. Al Marzouqi, O. Al Diabat, A. Alfarsi, R. Suson, M. Bash, S.A. Salloum, An empirical examination of the effect of TQM practices on hospital service quality: an assessment study in UAE hospitals, Syst. Rev. Pharm 11(9), pp. 347-362 (2020)

[15] T.L.H. Nguyen, K. Nagase, The influence of total quality management on customer satisfaction, International journal of healthcare management 12(4), pp. 277-285 (2019)

[16] T.L.H. Nguyen, K. Nagase, Patient satisfaction and loyalty to the healthcare organization, International Journal of Pharmaceutical and Healthcare Marketing (2021)

[17] A. Abu-Rumman, A. Mhasnah, T. Al-Zyout, Direct and indirect effects of TQM on the patients' satisfaction and loyalty in the Jordanian health care sector, Management Science Letters 11(2), pp. 493-502 (2021)

[18] A. Aburayya, M. Alshurideh, A. Al Marzouqi, O. Al Diabat, A. Alfarsi, R. Suson, M. Bash, and S.A. Salloum, An empirical examination of the effect of TQM practices on hospital service quality: an assessment study in UAE hospitals, Syst. Rev. Pharm 11(9), pp. 347-362 (2020)

[19] A. Al-Mhasnah, F. Salleh, A. Afthanorhan, and P.J.M.S.L. Ghazali, The relationship between services quality and customer satisfaction among Jordanian healthcare sector, Management Science Letters 8(12), pp. 1413-1420 (2018) 
[20] M.A. Daqar, M. Constantinovits, The role of total quality management in enhancing the quality of private healthcare services. Problems and Perspectives in Management 18(2), p. 64 (2020)

[21] T.L.H. Nguyen, K. Nagase, Total Quality Management: A Mediating Factor in the Relationship Between Customer Expectations and Satisfaction, International Journal of Management and Marketing Research 13(1), pp. 1-13 (2020)

[22] H.P. Daksith, U. Hewage, Total Quality Management \& Customer Satisfaction in Public Hospitals in Sri Lanka. In 2020 IEEE International Conference on Industrial Engineering and Engineering Management (IEEM), pp. 1246-1250 (2020)

[23] E. Sadeh, Interrelationships among quality enablers, service quality, patients' satisfaction and loyalty in hospitals, The TQM Journal 29(1), pp. 101-117 (2017)

[24] A.A. Jarrad, J.M. Joudeh, I.L. Mukattash, and A.G. Hassouneh, The effect of multidimensional service quality on word of mouth in university on-campus healthcare centers, The TQM Journal (2021)

[25] Y. Tsai, S.W. Wu, and Y.H. Tsai, Employee perceptions of service quality based on hospital quality improvement strategy, International Journal of Management, Economics and Social Sciences (IJMESS) 7, pp. 13-25 (2018)

[26] M.S. Mahmud, R.P. Lima, M.M. Rahman, and S. Rahman, Does healthcare service quality affect outbound medical tourists' satisfaction and loyalty? Experience from a developing country. International Journal of Pharmaceutical and Healthcare Marketing 15(3), pp. 429-450 (2021)

[27] T. Fatima, S.A. Malik, A. Shabbir, Hospital healthcare service quality, patient satisfaction and loyalty: An investigation in context of private healthcare systems, International Journal of Quality \& Reliability Management 35(6), pp. 1195-1214 (2018)

[28] E.B. Boadi, W. Wenxin, G. Bentum-Micah, I.K.J. Asare, and L.S. Bosompem, Impact of service quality on customer satisfaction in Ghana hospitals: A PLS-SEM approach. Canadian Journal of Applied Science and Technology 7(3) (2019)

[29] S.D. Baidoun, M.Z. Salem, and O.A. Omran, Assessment of TQM implementation level in Palestinian healthcare organizations: The case of Gaza Strip hospitals, The TQM Journal 30(2), pp. 98-115 (2018)

[30] A. Asnawi, Z. Awang, A. Afthanorhan, M. Mohamad, and F. Karim, The influence of hospital image and service quality on patients' satisfaction and loyalty, Management Science Letters 9(6), pp. 911-920 (2019)

[31] G. Rejikumar, A.A. Ajitha, and M.S. Nair, Healthcare service quality: a methodology for servicescape re-design using Taguchi approach, The TQM Journal 31(4), pp. 600619 (2019)

[32] B.A. Puthanveettil, S. Vijayan, A. Raj, and M.P. Sajan, TQM implementation practices and performance outcome of Indian hospitals: exploratory findings, The TQM Journal (2020)

[33] A. Aggarwal, H. Aeran, and M. Rathee, Quality management in healthcare: The pivotal desideratum, Journal of Oral Biology and Craniofacial Research 9(2), pp. 180-182 (2019)

[34] R. Rajan, P.R. Kumar, A Literature Review on the Effectiveness of TQM Implementation in Healthcare Sectors (Hospitals \& Medical Devices Servicing Industries), Asian Journal of Research in Social Sciences and Humanities 7(8), pp. 311-324 (2017)

[35] A. Shabbir, S.A. Malik, S.Y. Janjua, Equating the expected and perceived service quality: A comparison between public and private healthcare service providers, International Journal of Quality \& Reliability Management 34(8), pp. 1295-1317 (2017) 
[36] A. Aburayya, A. Marzouqi, D. Alawadhi, F. Abdouli, and M. Taryam, An empirical investigation of the effect of employees' customer orientation on customer loyalty through the mediating role of customer satisfaction and service quality, Management Science Letters 10(10), pp. 2147-2158 (2020)

[37] S.A. Javed, F. Ilyas, Service quality and satisfaction in healthcare sector of Pakistanthe patients' expectations, International journal of health care quality assurance 31(6), pp. 489-501 (2018)

[38] M. Alshurideh, An Investigation of the Effect of Lean Six Sigma Practices on Healthcare Service Quality and Patient Satisfaction : Testing the Mediating Role of Service Quality in Dubai Primary Healthcare Sector. Jour of Adv Research in Dynamical \& Control Systems 12 (2020) 